\title{
ARQUITECTURAS REINVENTADAS. HOTELES SOSTENIBLES EN CONSTRUCCIONES INDUSTRIALES
}

\author{
Carmen Adams* \\ Universidad de Oviedo \\ https://orcid.org/0000-0003-1230-6528
}

\section{RESUMEN}

Se realiza en este trabajo un recorrido por restos industriales en desuso reconvertidos en hoteles, evidenciándose que la reutilización de estos viejos contenedores para nuevos usos turísticos ha servido por una parte para recuperar patrimonio, mientras por otra se logra una actuación sostenible que evita el despilfarro que supone la nueva construcción. No obstante, queda de relieve también la paradoja de actuaciones de rehabilitación, donde la reutilización puede conllevar un deterioro ambiental, pese a la recuperación patrimonial que en principio supone.

Palabras clave: patrimonio industrial; hotel; turismo; sostenibilidad.

\section{Reinvented architectures. Sustainable hotels in industrial constructions}

\section{ABSTRACT}

This work includes a tour of disused industrial remains transformed into hotels, It is evident that the reuse of these old containers in order to new tourist uses has helped on the one hand to recover heritage, while on the other hand a sustainable action is achieved and it avoids the waste that implies the new construction. However, the paradox of rehabilitation actions is also highlighted, where reuse can lead to environmental deterioration, despite the recovery of heritage that initially it means.

Keywords: Industrial heritage; hotel; tourism; sustainability.

Fecha de recepción: 23 de junio de 2020.

Fecha de aceptación: 26 de abril de 2021.

* Departamento de Historia del Arte y Musicología. Universidad de Oviedo. Campus del Milán. Amparo Pedregal s/n. 33011 OVIEDO (España).E-mail: adamsf@uniovi.es 


\section{INTRODUCCIÓN}

Para afrontar el tema de una sostenibilidad resiliente en lo relativo a las edificaciones turísticas en nuestro país, es decir desde una sostenibilidad dinámica, hay que plantear el tema al menos en dos entornos.

a) Por una parte, la integración o relación que se establece entre el inmueble y el paisaje y por otra las cuestiones relacionadas con la autosuficiencia energética, las emisiones, los edificios pasivos etc.

Sostenibilidad e integración respecto al territorio/paisaje, ya sea éste urbano o rural: Impacto volumétrico, impacto estético-formal. Comunicación entre el inmueble y el paisaje, que lo natural penetre en el espacio interno. Implicación del establecimiento o conjunto con su entorno, por medio de programas de conservación medioambiental

a) b) Autosuficiencia energética: "Edificios pasivos", geotermia, orientación, volúmenes que se autoorganicen y vegetación adecuada para generar zonas de sombras en lugares cálidos, aislamiento térmico de los inmuebles (recubrimiento de paramentos, triple acristalamiento, cámara de aire bajo suelo), iluminación natural, leds...

Y junto a ello hay que considerar un eje transversal: La sostenibilidad de la sostenibilidad, es decir la resiliencia. Para ello se hace necesario abordar diversas cuestiones:

- Actuaciones bioclimáticas de bajo coste tanto en su ejecución como en su mantenimiento: balsas de agua en azoteas para enfriar edificios, chimeneas de ventilación que refrescan de forma natural, cubiertas vegetales, agua caliente termal para la calefacción o residual procedente por ejemplo de centrales térmicas

- Rehabilitación frente a nueva construcción

- Optimización de recursos. Prefabricados o materiales locales que tradicionalmente han funcionado en la zona.

- Construcción/Reconstrucción bioclimática: materiales reciclables, disminución del consumo energético, energías renovables, reducción del precio de construcción y mantenimiento.

- Renovación integral de áreas degradadas. Nuevos usos: por ejemplo, transformación de algunas de estas zonas en ciudades del bienestar para mayores.

\section{OBJETIVOS}

Para este trabajo se ha escogido el segundo enunciado: Rehabilitación frente a nueva construcción, por entender la necesidad de analizar cada uno de los enunciados, para lograr en sucesivos estudios una propuesta holística que supere las partes por separado.

El enfoque así es claro: enfatizar la necesidad de recuperar viejos patrimonios para, refuncionalizándolos, lograr su preservación y puesta en valor.

Si bien el panorama general de la construcción hotelera española de las últimas décadas en ámbito rural presenta una clara tendencia hacia el Regionalismo en sus diversas 
acepciones, son de destacar algunas actuaciones que destacan por una apuesta valiente por la modernidad. Intervenciones no por escasas menos importantes. Modernidad entendida no sólo como alarde formal, si no como experimentación con materiales, líneas, y sobre todo una comprensión del paisaje, integración en el entorno y una necesaria sensibilidad hacia los temas de sostenibilidad de cara al siglo XXI. Junto a ello, se distinguen también arquitecturas que parten de esos mismos principios de resiliencia y que son aquellas fruto de la rehabilitación de patrimonio en desuso, que así adquiere nueva función, al tiempo que supone una mejora ambiental.

Partimos así de la necesaria atención a las construcciones en su entorno y en su ambiente. La consideración del patrimonio, por parte de la UNESCO, como un todo que integra lo natural y lo cultural, sin bordes precisos, con una concepción global lo encontramos ya desde 1964 en la Carta de Venecia, donde se señala explícitamente que "La noción del monumento histórico comprende tanto la creación arquitectónica aislada, como el ambiente urbano o paisajístico que constituya el testimonio de una civilización particular...”. Y ello viene refrendado en París en 1972 durante la Convención parta la Protección del Patrimonio Mundial, Cultural y Natural.

Viejos contenedores para nuevos usos, un planteamiento patrimonial moderno, propio de esos años ochenta. La toma de conciencia de qué el patrimonio restaurado debe dotarse de nuevas funciones si, perdidas las iniciales, se pretende su permanencia Es lo que ya planteaba Alöis Riegl a principios del siglo XX, cuando hace referencia al valor de contemporaneidad instrumental del monumento (Riegl, 1999). Y en España, ya desde la Comisaría Regia de Turismo (1911-28) y el Marqués de la Vega Inclán, y a partir de 1928 desde el Patronato Nacional de Turismo se aboga por recuperar patrimonio para albergar hoteles. La Red de Paradores Nacionales será un ejemplo, pero también iniciativas regionales como la Red de Hospederías de Extremadura (a partir de la década de los 90) o la marca Pazos de Galicia.

Hay que considerar que ya desde la Declaración de Manila sobre Turismo Mundial (1980) se señala que el turismo puede contribuir positivamente a la vida de la nación mediante una oferta que proteja y respete el patrimonio cultural. Asimismo, en la Carta Internacional sobre Turismo Cultural (1999) se alude explícitamente a la interacción dinámica entre turismo y patrimonio cultural, y se hace referencia a lo que conlleva el turismo para el intercambio cultural, como la implicación de las comunidades locales en la planificación, los beneficios que para ésta trae el turismo, y también los efectos positivos sobre la protección del propio patrimonio. En el Código ético mundial para el Turismo de 2001, se hace referencia al turismo como factor de aprovechamiento y enriquecimiento del patrimonio cultural de la humanidad. Asimismo, se señala que los recursos turísticos pertenecen al patrimonio común de la humanidad. Se alude al respeto al patrimonio artístico, arqueológico y cultural. Y se destaca la importancia de revertir los recursos obtenidos en mantener el patrimonio. Por su parte, la Cumbre Mundial del Turismo Sostenible, celebrada en Vitoria en 2015, publica la Carta Mundial de Turismo Sostenible +20, que considera que el turismo puede y debe ser fuerza motriz del patrimonio cultural y las industrias creativas. 


\section{METODOLOGÍA}

Para afrontar este trabajo se partió de estudios previos elaborados durante años por la autora sobre arquitecturas hoteleras, tanto en su vertiente tipológica como en la relación de esas construcciones con su entorno y las repercusiones en el paisaje.

Por otro lado, se rastrearon ejemplos ofertados en la red a fin de lograr un número de establecimientos suficientes para lograr establecer tipologías y marcos de actuación. Después se buscó información relativa a proyectos, arquitectos y en algunos casos la repercusión ambiental.

Simultáneamente, se realizó el correspondiente trabajo de campo y se contactó con establecimientos y arquitectos implicados en los trabajos de rehabilitación.

\section{HOTELES A PARTIR DE ARQUITECTURA PREINDUSTRIAL, INDUS- TRIAL, EMPRESARIAL O SOCIAL}

Si bien estamos habituados a encontrar hoteles reutilizando viejos palacios casonas o edificios residenciales de calidad, aquí nos vamos a centrar en la recuperación de inmuebles de carácter industrial, preindustrial o bien destinados a usos sociales o empresariales.

El recurrir a casonas erigidas en el pasado para, tras un proceso de rehabilitación y adaptación, proceder a su transformación funcional con vistas a su aprovechamiento turístico no es algo ni nuevo ni privativo de la zona. (Adams, 2017). De hecho, ya a finales del siglo XIX encontramos esta tendencia en ámbitos de turismo precoz, como por ejemplo Canarias, donde convive con el levantamiento de hoteles de nueva planta. (Hernández Gutiérrez, 1991) En la actualidad esto continúa con numerosos ejemplos de palacios reconvertidos a hoteles en las islas: Hotel R. Senderos de Abona en Granadilla de Abona a partir de una casa señorial del siglo XIX, o el Hotel Rural Orotava en una casa de 1585, entre otros muchos ejemplos.

Y en el resto de España son numerosos los exponentes de esta práctica La toma de conciencia de qué el patrimonio restaurado debe dotarse de nuevas funciones si, perdidas las iniciales, se pretende su permanencia (Adams, 2004). Es lo que ya planteaba Alöis Riegl a principios del siglo XX, cuando hace referencia al valor de contemporaneidad instrumental del monumento (Riegl,1904). Y en España, ya desde la Comisaría Regia de Turismo (1911-28) y el Marqués de la Vega Inclán, y a partir de 1928 desde el Patronato Nacional de Turismo se aboga por recuperar patrimonio para albergar hoteles. La Red de Paradores Nacionales será un ejemplo, pero también iniciativas regionales como la Red de Hospederías de Extremadura (a partir de la década de los 90) o la marca Pazos de Galicia.

Lo que resulta singular es la elección de inmuebles no residenciales para función como instalaciones hoteleras: edificios que fueron fábricas, molinos, cuarteles, faros o estaciones. Y esta realidad se puede rastrear en muchos ejemplos españoles, algunos de los cuales se detallan a continuación.

Por supuesto, también hay muestras interesantísimas en otros países: la habitación en una grúa del Harbour Crane B\&B en Amsterdam, el Celica en Liubliana ubicado en una antigua cárcel, el Arena Hotel en una plaza de toros de 1866 en México, el Mc Menamin's Kennedy School en una antigua escuela en Estados Unidos que conserva pizarras y bancos originales, molinos de viento en Santorini, un hotel en el antiguo faro Harlingen en Amsterdam, en un 
tren en Estados Unidos (B\&B Cabos oses) o también en ese país el Train Station Hotel en una antigua estación neorrománica de 1888, o el Hotel Singular en Puerto Natales (Chile) donde el arquitecto Pedro Kovacic realizó una intervención espléndida sobre el antiguo Frigorífico Bories (1915) erigido para el tratamiento de la carne de oveja.

\section{Figura 1 \\ HOTEL CELICA (LIUBLIANA)}

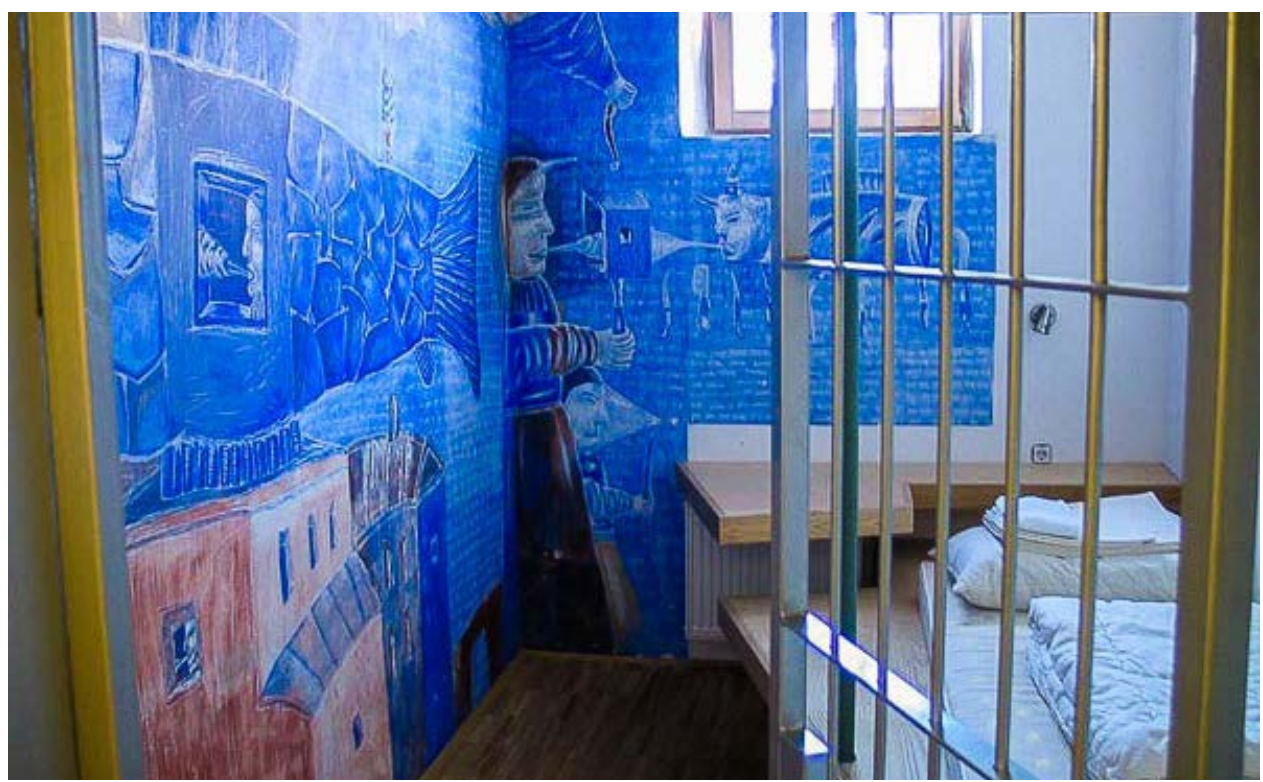

Fuente: https://www.ljubljana.info/hostels/celica/

Haciendo un recorrido por los ejemplos más significativos de este cambio de uso en territorio nacional, podemos establecer varios subconjuntos.

\subsection{Molinos. La atracción del sonido del agua}

El agua que fluye, los ríos, las cascadas ejercen un poderoso atractivo para la arquitectura. Quizás el ejemplo más emblemático lo constituya la Casa de la Cascada de Frank Lloyd Wright: la residencia Kaufmann construida entre 1936 y 1939 sobre una cascada del río Bear Run, en Pensilvania, ejemplo de la integración del agua en la construcción, sin que ésta domine en realidad a la naturaleza que fluye con fuerza.

En Llanes (Asturias) se encuentra El Molino de Tresgrandas (1996-97), que forma parte del Club de Calidad Casonas Asturianas. Aquí, la arquitecta Carmen Berrini ${ }^{1}$ parte

\footnotetext{
1 Carmen Berrini es autora también de otros hoteles en el concejo, como la Finca Arredondo, que realizó recuperando tres volúmenes preexistentes, siempre con el planteamiento de "mantener una historia", ya que según ella misma se encarga de resaltar: "el patrimonio no es sólo el monumento". Intenta así preservar conjuntos
} 
de un antiguo molino harinero y otra construcción anexa que transforma en hotel de 8 habitaciones, respetando el conjunto de quintana y recuperando materiales tradicionales. En el proyecto inicial no se habilitaba bajo cubierta en el volumen más bajo, lo que conseguía un resultado más armónico, ya que el exceso de verticalidad final, unido al remate en frontón, desvirtúa en parte el conjunto.

En todo caso, el resultado es atractivo, habiéndose sabido conservar -tal como se describe en la publicidad del establecimiento- la tradicional construcción de piedra y madera. Sin embargo, es muy interesante cómo se ha acudido a soluciones novedosas: así el recurso a la plancha de cristal en el suelo, con el fin de que quede a la vista el discurrir del agua que movía la rueda. Este mismo planteamiento lo hemos rastreado en otros hoteles habilitados a partir de un construcciones similares, como por ejemplo en el Molino de los Gamusinos en Tolbaños (Ávila), donde el suelo acristalado del salón permite apreciar el discurrir del agua. Igualmente, el recurrir a un antiguo molino para crear un establecimiento hotelero lo encontramos en otros lugares, incluso fuera de nuestras fronteras: destacar el caso de la iniciativa realizada en New Lanark, en Gran Bretaña, donde se ha creado un parque temático a partir de los restos del sueño de Owen. Allí también el viejo molino acoge ahora un hotel.

El Molino de Tresgrandas ha habilitado también otra construcción tradicional, un hórreo, para convertirlo en sala de juegos. La recuperación o construcción de hórreos para complementar las instalaciones la encontramos en otros establecimientos de la zona como La Arquera, La Posada de Babel o La Quintana del Cuera. Vemos así el recurso a la tradición, a la cultura popular y rural, a ofrecer al visitante la Asturias que busca, la que previamente a conocido a través de las imágenes, y que ahora pretende aprehender. Es interesante reseñar que la oferta de este hotel no se queda sólo en los recursos turísticos habituales, ya que plantea actividades diversas como la recogida de setas con el asesoramiento de un micólogo, cursillos de elaboración de quesos o sidra, que le valió en 1999 el Premio al Mejor Producto de Turismo Cultural en FITUR e incluso lo que denominan "fin de semana detectivesco", que convierte al huésped en protagonista de un novela negra por unos días, y que obtuvo el Premio al Mejor Producto de Turismo en la Naturaleza en la edición de 2004 de la misma feria.

\subsection{El ferrocarril como destino turístico}

La visión romántica del tren. El ferrocarril como utopía y modernidad ha gozado de gran consideración desde sus inicios (Adams, 2004) En urbanismo y también en literatura o filmografía. Howard, Garnier, Henard o Arturo Soria lo consideraron imprescindible en sus ciudades del futuro.. Y es que el traqueteo de la locomotora parece ligado a un mundo onírico con cierto halo de misterio o lujo: el Transiberiano, el Orient Express. Confort y sofisticación; pero también igualitarismo, descongestión, ruidez, sostenibilidad y acercamiento de culturas. En el Macondo de García Márquez, el progreso llega en forma de "una cocina arrastrando un pueblo".

y no sólo edificios aislados vacíos de contenidos, tal como se viene planteando desde las ideas de Sitte. Otro de sus trabajos, el hotel Casona de Alevia, emplazado en esta localidad de Peñamellera Baja, parte igualmente de una vieja construcción que de esta forma se recupera para el turismo. 
Así, se aparece el tren como atracción, como destino turístico, convertidas sus instalaciones en hoteles.

En la comarca turolense de Matarraña se ubica el hotel La Parada del Compte, aprovechando la antigua estación de ferrocarril de Torre del Compte. La estación había permanecido más de veinte años cerrada hasta que fue adquirida en 1996 por sus propietarios, Pilar Vilés y José María Naranjo. Es destacable este interés mostrado por una instalación del patrimonio industrial, un patrimonio que todavía hoy, y tras décadas de esfuerzos, cuesta trabajo hacer comprender, valorar y conservar.

Los espacios son amplios, de un cuidado y atrevido cromatismo. Las paredes de ladrillo visto y los techos de madera contrastan con un mobiliario ligero y moderno y una interesante colección de pintura de artistas jóvenes. Destaca la distribución interna, con una planta baja que acoge el vestíbulo, recepción y el restaurante, y una superior a la que se accede por medio de una estilizada y etérea escalera. En este piso alto, se abre un amplio salón, a modo de loft, donde el confort va unido al diseño y el buen gusto.

\section{Figura 2 \\ LA PARADA DEL COMPTE (TERUEL)}

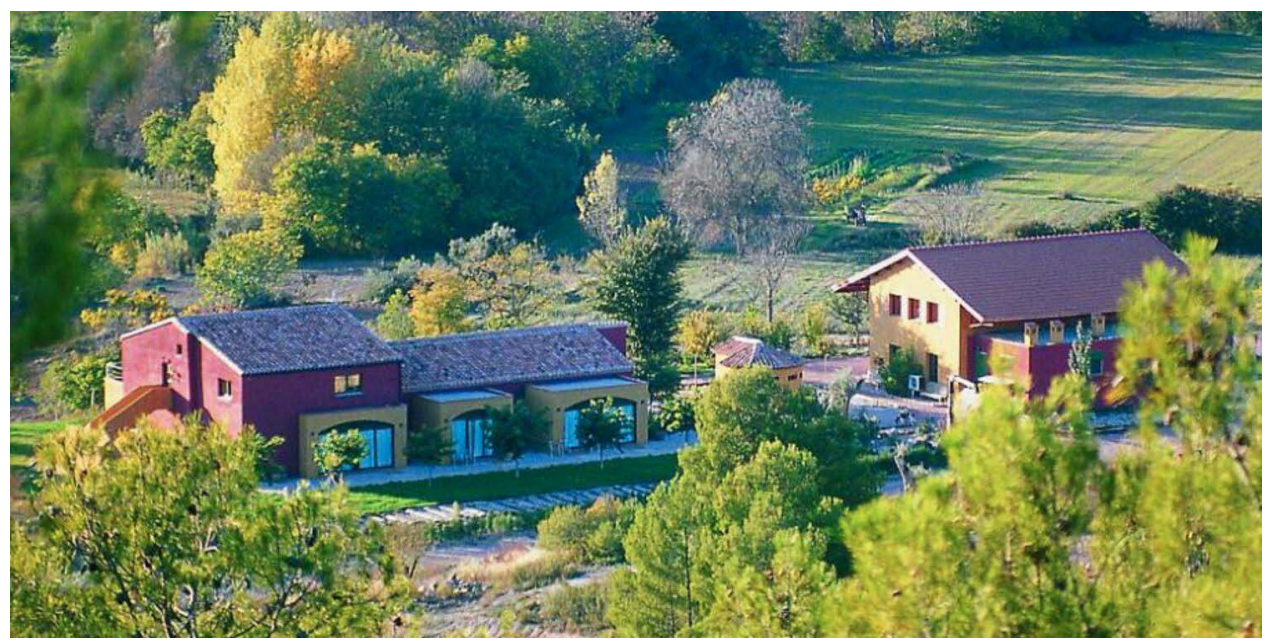

Fuente: https://www.privateaser.es/local/19740-hotel-la-parada-del-compte

Hay que señalar que hemos podido rastrear otros ejemplos de alojamientos rurales a partir de una estación de tren. Así en la localidad soriana de Almazán abre sus puertas el Centro de Turismo Rural Estación La Dehesa, ubicado en una antigua estación, construida en 1895.

Muy interesante resulta el caso de la Sierra de Cádiz. Allí un fallido proyecto de ferrocarril dejo una calzada sin vía y estaciones sin uso. Iba a ser un tren que uniera Jerez y Almargen. Todo ello es ahora una vía verde de $36,5 \mathrm{~km}$ que va de Olvera a Puerto Serrano, y donde se han utilizado las infraestructuras para uso turístico. Así, esas estaciones nunca inauguradas son ahora hoteles: El Vía Verde de Olvera , La Antigua Estación en Villa- 
martín, El Conjunto Turístico Rural Estación de Puerto Serrano 'Puerta de la Sierra que dispone de seis habitaciones en la casa básica (antigua estación de tren) y de ocho casas rurales. El hotel restaurante Estación de Coripe consta de dos plantas, dispone de bar, restaurante y aseos. En la planta superior se ubican los alojamientos.

La historia de esta vía se remonta a principios del siglo XIX. En 1887 se presentó un anteproyecto que contemplaba una línea desde Jerez a Setenil, con un ramal que finalizaba en Grazalema. Ya en el XX se crea en Jerez la Sociedad para los Estudios del Ferrocarril Jerez-Villamartín-Setenil. Y en 1926 se aprueba el proyecto del ferrocarril de la sierra; pero el fin de la Dictadura de Primo de Rivera y motivos económicos impidieron que se terminara.

Esta iniciativa gaditana se complementa con una curiosa oferta de alojamiento: La Casa Vagón Vía Verde de la Sierra. El recurrir a vagones de tren como oferta turística es algo generalizado en muchos lugres (aunque en este caso se trata de recreaciones del proyectado ferrocarril de la sierra). Así en España hay ejemplos como El Vagón de Baides en Guadalajara, donde se recuperaron dos vagones de los años 60 y 70 del siglo XX, o El Vagón de Reyes en Madrid. Y por toda Europa proliferan muestras, como evidencia la página de airbnb, con propuestas en Francia, Reino Unido y Países Bajos. Y por supuesto en Estados Unidos. Y es que las iniciativas para dormir en lugares inusuales abundan en todo el mundo: cárceles, colegios, templos, casas en árboles, hoteles submarinos, flotantes, suites subterráneas, en minas, hoteles llenos de muñecos, de payasos...2

En este recorrido por las instalaciones ferroviarias es necesario mencionar como curiosidad el edificio que se levanta en el número 83 de la calle Atocha de Madrid, aunque se trate de un establecimiento urbano. Construido en 1914-16 (con proyecto de 1913) por el ingeniero José María Otamendi Machimbarrena junto a Ricardo García Guereta (Campos Setién, 2015) para la Asociación de Empleados y Obreros de los Ferrocarriles de España. Actualmente alberga el Hotel Tryp Madrid Atocha y conserva gran parte de la decoración original en las zonas comunes.

José María Otamendi Machimbarrena en colaboración con su hermano Julián será autor de dos emblemáticos inmuebles madrileños de posguerra: Edificio España ${ }^{3}$ (194753) y Torre de Madrid (1954-57).

Por su parte, Guereta, arquitecto experto en restauración de patrimonio (como evidencia su trabajo en las catedrales de Salamanca o en San Martín de Teruel) dedica gran parte de su obra al tema social: asilos, hospitales...

La Asociación de Empleados y Obreros de los Ferrocarriles de España era entonces la más importante de las asociaciones ferroviarias que ya aquel año superaba los 25.000 afiliados. Destaca Salvador Mata Pérez (Mata Pérez, 2013) el enorme desarrollo del salón de actos, sólo superado en importancia por la escuela Y también como las vidrieras polícromas, escaleras nobles, salones... parecen entroncar más con un diseño de ocio burgués que con espacios obreros de la época.

2 Hay numerosas páginas en internet dedicadas al tema. Como muestra https://www.harpersbazaar.com/ es/cultura/viajes-planes/a22639493/hoteles-mas-extranos-mundo

También publicaciones como VV.AA (2008): Extreme hotels, Editorial Estampa. Lisboa.

3 El Edificio España ha sido recientemente objeto de una rehabilitación integral con vistas a su transformación en establecimiento hotelero. 


\section{Figura 3 \\ EDIFICIO DE LA ASOCIACIÓN DE EMPLEADOS Y OBREROS DE LOS FERROCARRILES DE ESPAÑA}

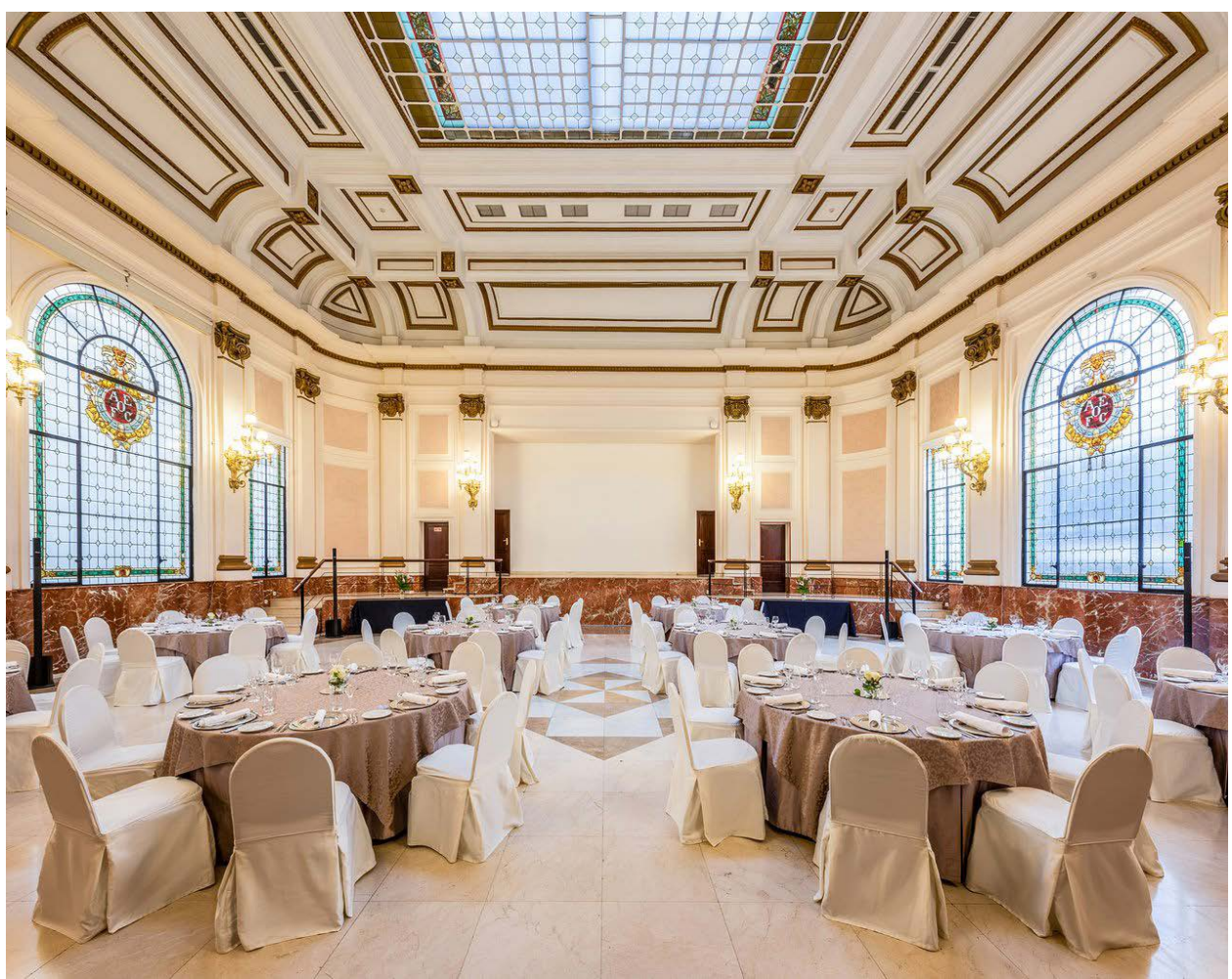

Fuente: https://goo.gl/maps/LktSKsoaJMBweu74A

Es oportuno mencionar también una interesante iniciativa en Mérida: Deluxe Hostel \& Suites. La reconversión de la antigua residencia ferroviaria, construida en la década de 1950 para dormitorio de agentes de Renfe, más tarde fue utilizada como local sindical y posteriormente en desuso. Situada en el recinto de la estación de Mérida, alojó a maquinistas, interventores y otros agentes. Es un edificio de dos plantas con una superficie construida de 740 metros cuadrados.

ADIF alquiló el inmueble en 2016 a la empresa Residencias, Hoteles y Albergues de Extremadura (Rehalex), que lo ha reconvertido en un establecimiento hotelero de la fórmula "hostel" (albergue-hostal). Este contrato se realizó en el marco de política de Responsabilidad Corporativa de ADIF.

Rehalex se comprometió a realizar una inversión de 364.000 euros para adaptar el edificio al uso convenido, aunque la inversión real de las obras fue finalmente de 420.000 euros en obra, además los costes para equipamiento. El Hostel que cuenta con veinte habi- 
taciones y una capacidad máxima de 53 plazas, ha generado nueve puestos de trabajo de los que ocho son discapacitados físicos.

\section{Figura 4 \\ PLANO DE LUXE HOSTEL \& SUITES MÉRIDA}

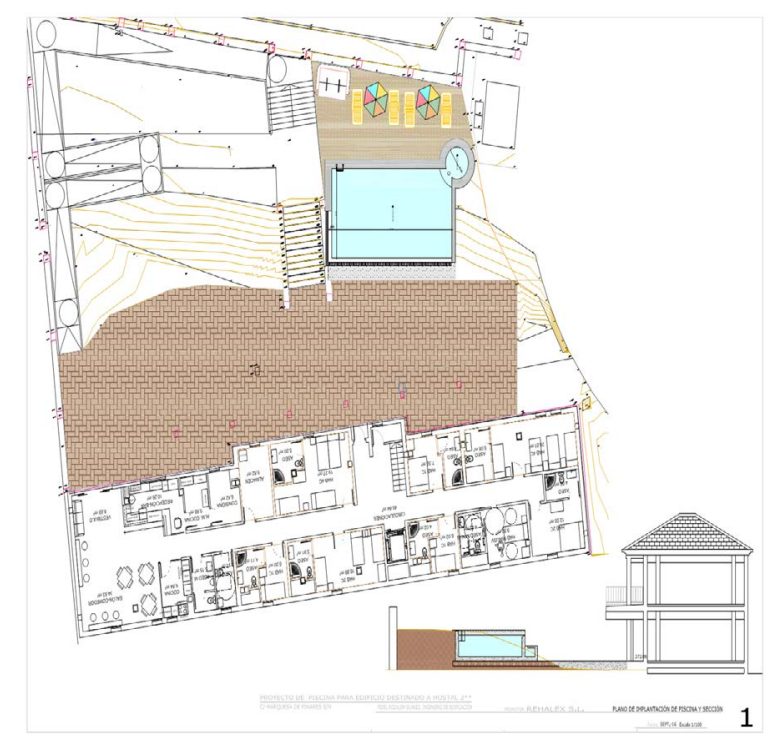

En Extremadura este programa de "Activos Emprendedores" tiene otros proyectos en marcha. Es el caso, a pocos metros del nuevo Hostel de Mérida, del Centro de Ocio Joven (antiguo economato ferroviario), "Casa Roja" en la estación de Llerena, dedicado a Centro de Rehabilitación e Inserción de Drogodependientes, el de un inmueble en la estación de Zafra, gestionado por la Asociación Síndrome de Down, o los centros de transeúntes y sin techo gestionados por Cáritas de Cáceres y Mérida.

En otras ocasiones son establecimientos dedicados antaño a otros usos de transporte los que se reforman, y se dotan de nueva función hotelera, como la Cabaña Real de Carreteros en Casarejos, también en Soria.

\subsection{Hoteles en faros. La atracción de lo sublime}

La tempestad, la naturaleza en toda su dimensión trágica vista desde los confines de la tierra, donde se alzan desde antiguo las luces que guían a los navegantes entre tanta inmensidad han llamado siempre la atención. Polos de sentimientos encontrados entre la atracción y el temor aúnan los elementos de la poética de lo sublime. Contemplar un mar embravecido desde un faro es, por ello, un recurso turístico que se ha sabido aprovechar en algunas zonas que especialmente se prestan a esta visión romántica de las costas batidas 
por las aguas. Así ocurre en Galicia, donde las ciclogénesis forman parte de lo cotidiano (Sotelo Navalpotro y Sotelo Pérez, 2018).

O Semaforo de Fisterra. Construido en 1879 para emitir señales a buques de guerra, esta edificación integra las instalaciones del faro más antiguo de la Costa da Morte (1853), complementado con La Sirena (1888) popularmente conocida como la vaca de Fisterra, obra de Ángel García del Hoyo (su función era guiar a los navegantes cuando la niebla impedía ver la luz del faro). El faro de Fisterra se erige dentro del Plan General de Alumbrado Marítimo de 1847 encargándosele el proyecto al ingeniero Félix Uhagón, autor de los faros de Machichaco y Estaca de Bares. Este emblemático inmueble alberga desde 1999 un hotel. En 2016 fue objeto de reforma por el estudio del arquitecto César Portela $^{4}$. Es un establecimiento pequeño que acoge 5 habitaciones, restaurante y ofrece impresionantes vistas desde sus terrazas. Dos faros, Dos naufraxios, Dos ventos... son los evocadores nombres de los dormitorios. Junto a Portela trabajó el estudio de interiores pQliar Consulting y Gonzalo Liñeiro.

\section{Figura 5 O SEMAFORO DE FISTERRA}

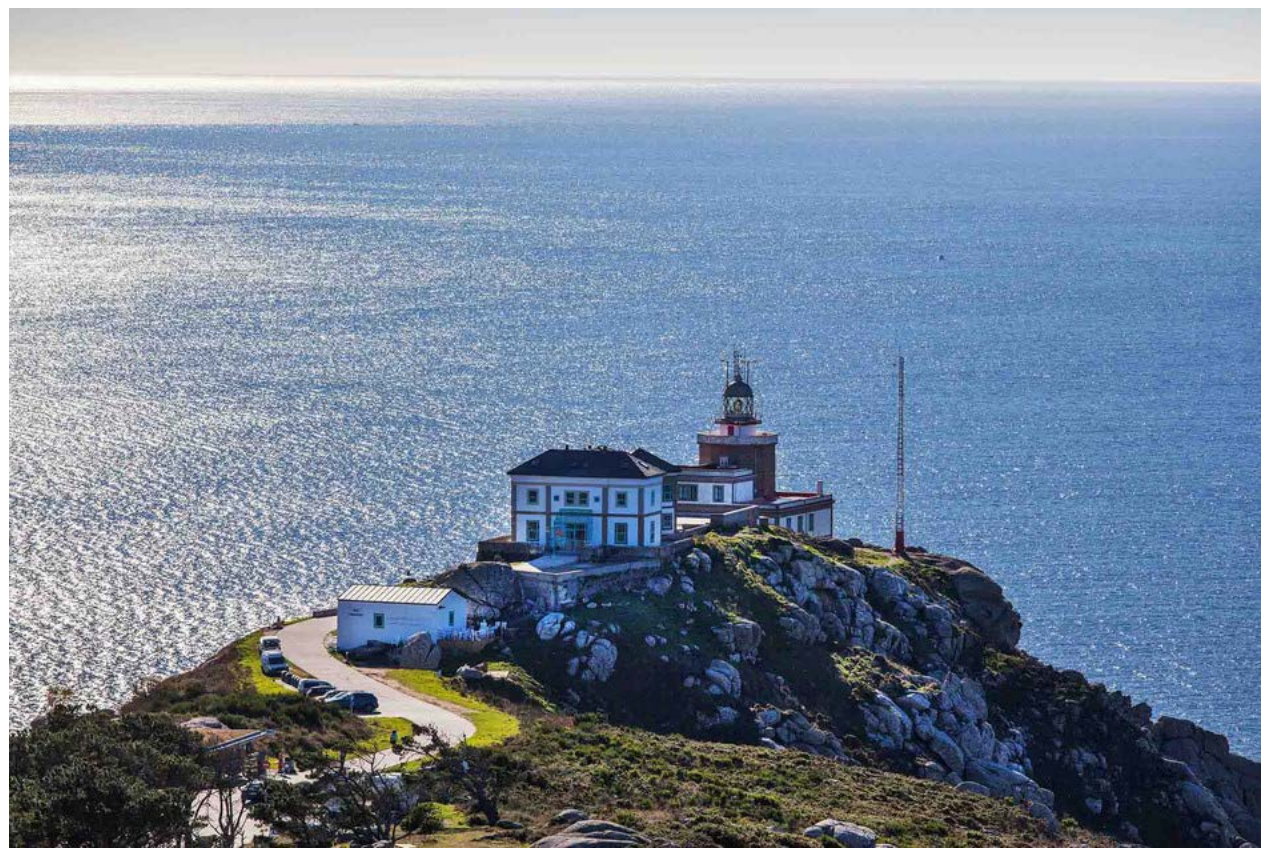

Fuente: https://www.traveler.es/naturaleza/articulos/o-semaforo-de-fisterra-hotel-en-faro-costa-da-morte-galicia/ 15323

4 César Portela Fernández-Jardón es Premio Nacional de Arquitectura y uno de los principales exponentes de la arquitectura gallega y española del siglo XX. Autor de obras emblemáticas como el Domus de A Coruña junto a Arata Isozaki o la Casa del Mar de Vigo, en colaboración con Aldo Rossi. 
Es de destacar que Portela había estudiado a fondo el mundo de los faros, sus implicaciones en el paisaje ya desde que proyecta el Faro de Punta Nariga (1989-1990) en Malpica ( A Coruña). Declara Urrutia (1997) de esta obra: "Estático e imponente los días de calma, pero dinámico y tenso los de tempestad. La tipología es clásica, intemporal, resultado de una conjunción entre el lugar, el programa y los materiales". Sabe así Portela de faros, de su función, de su poética.

En el viejo faro de Ribadeo, erigido en Isla Pancha en 1857 es hoy un hotel. El edificio mantuvo su uso hasta 1983, cuando se erigió el faro nuevo. El nuevo uso tuvo como punto de partida el plan para reconversión de antiguos faros en establecimientos turísticos de 2013

Más antiguo es el hotel Semáforo de Bares. Se trata de una antigua construcción militar, cuya función era, a finales del siglo XIX, la comunicación con los barcos mediante señales con banderas, puesto de observación militar y centro meteorológico. Mantuvo su uso hasta finales de la década de los 60. En 2002 abrió sus puertas como establecimiento hotelero.

\subsection{Centrales eléctricas, fábricas, secaderos, almazaras, plazas de toros, cortijos...}

Junto a estos conjuntos de instalaciones ferroviarias, faros o molinos, se encuentran otro tipo de restos industriales o empresariales reconvertidos en hoteles.

En Asturias se emplaza un establecimiento singular: Zentral Club. Aquí se parte de una antigua central eléctrica, la de Selviella en Belmonte de Miranda para organizar un curioso núcleo de turismo rural, donde se fusionan las viejas instalaciones, que conservan incluso La maquinaria original, con construcciones nuevas donde la imaginación desbordante de su creador, el madrileño Ismael Calzón Gómez ha ido generando recintos de regusto secesión y decó que parecen surgir de la propia central primigenia.

En el País Vasco, abrió sus puertas el Hotel One Shot Tabakalera, situado en el Centro Internacional de Cultura Contemporánea Tabakalera. El edificio, renovado por completo en 2015, fue la antigua fábrica de tabacos de San Sebastián. El proyecto corrió a cargo del estudio Alfaro-Manrique.

En Extremadura, otro ejemplo de apuesta por la modernidad lo hallamos en el Hotel Rural El Turcal, ubicado en Torremenga de La Vera en Cáceres. El establecimiento se asienta en un antiguo secadero de pimentón y unas tinadas (antiguas edificaciones de ganadería) de comienzos del pasado siglo. Según se destaca en la publicidad "La rehabilitación del conjunto se ha realizado respetando la estructura y materiales originales, todo ello al servicio de una arquitectura bioclimática de vanguardia". 


\section{Figura 6 \\ ZENTRAL CLUB}

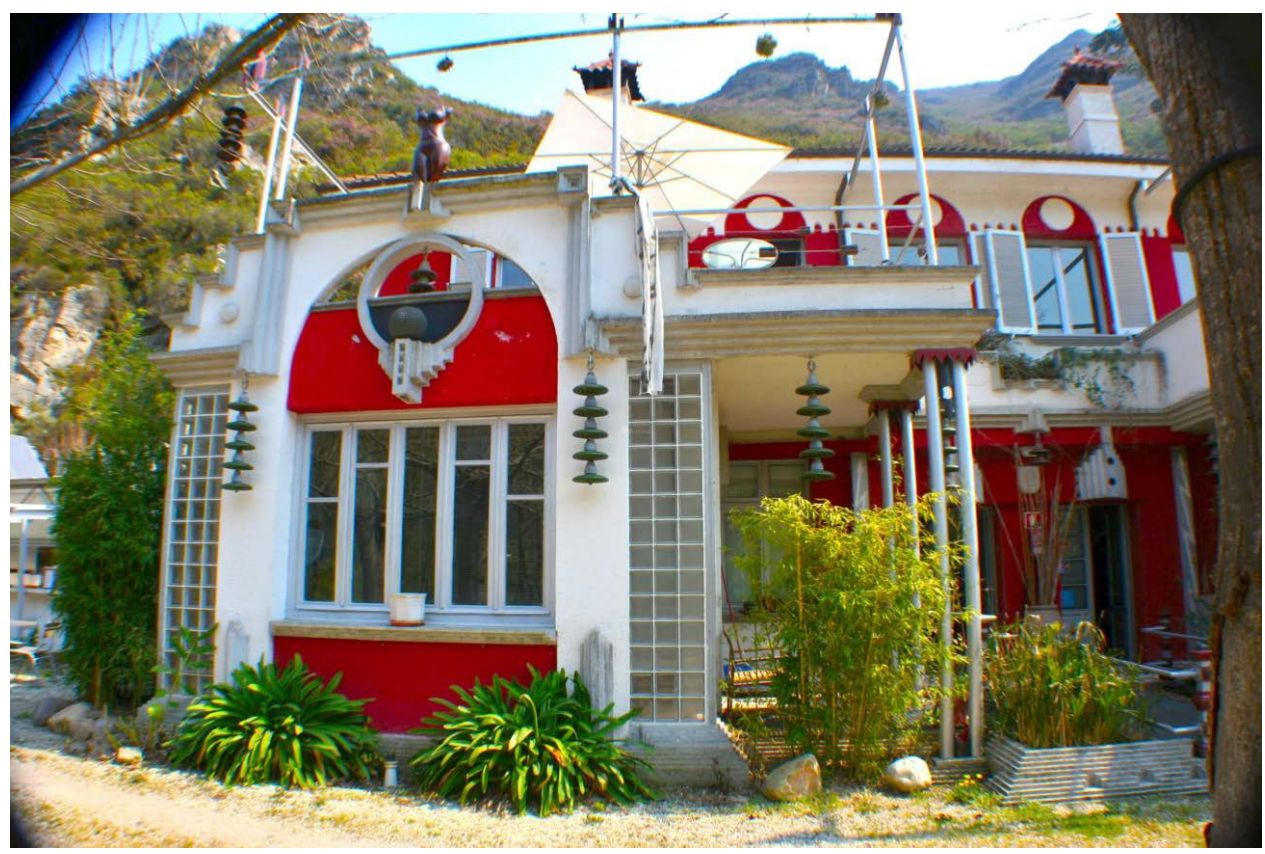

Fuente: https://www.clubrural.com/apartamentos-turisticos/asturias/belmonte-de-miranda/apartamentos-zentralclub_135806/fotos

El hotel dispone de 11 habitaciones, 8 dobles y 3 especiales, y combina con gran acierto los materiales tradicionales de la primitiva construcción, con un gusto por la simplicidad y sinceridad moderna, en sus pies derechos vistos, o la ausencia de concesiones en las partes de nueva obra, destacando el vanguardista diseño de la escalera metálica.

En Extremadura, la Red de Hospederías (Abujeta, 2015) presenta algún ejemplo singular, susceptible de ser reseñado aquí. Así, la Hospedería de Hurdes Reales, ubicada en la alquería de Las Mestas, dentro del municipio cacereño de Ladrillar. Aquí se partió de una de las factorías que el Real Patronato de Hurdes levantó en la zona, con vistas a albergar la escuela, el dispensario médico y la casa-cuartel de la Guardia Civil. Este patronato fue creado por Alfonso XIII tras su famoso viaje por la comarca hurdana, en la que quedó impresionado de la miseria, falta de higiene, endogamia y aislamiento de la zona; situación que mostraría después al mundo el celuloide de Buñuel. 


\section{Figura 7 \\ HOSPEDERÍA DE HURDES REALES}

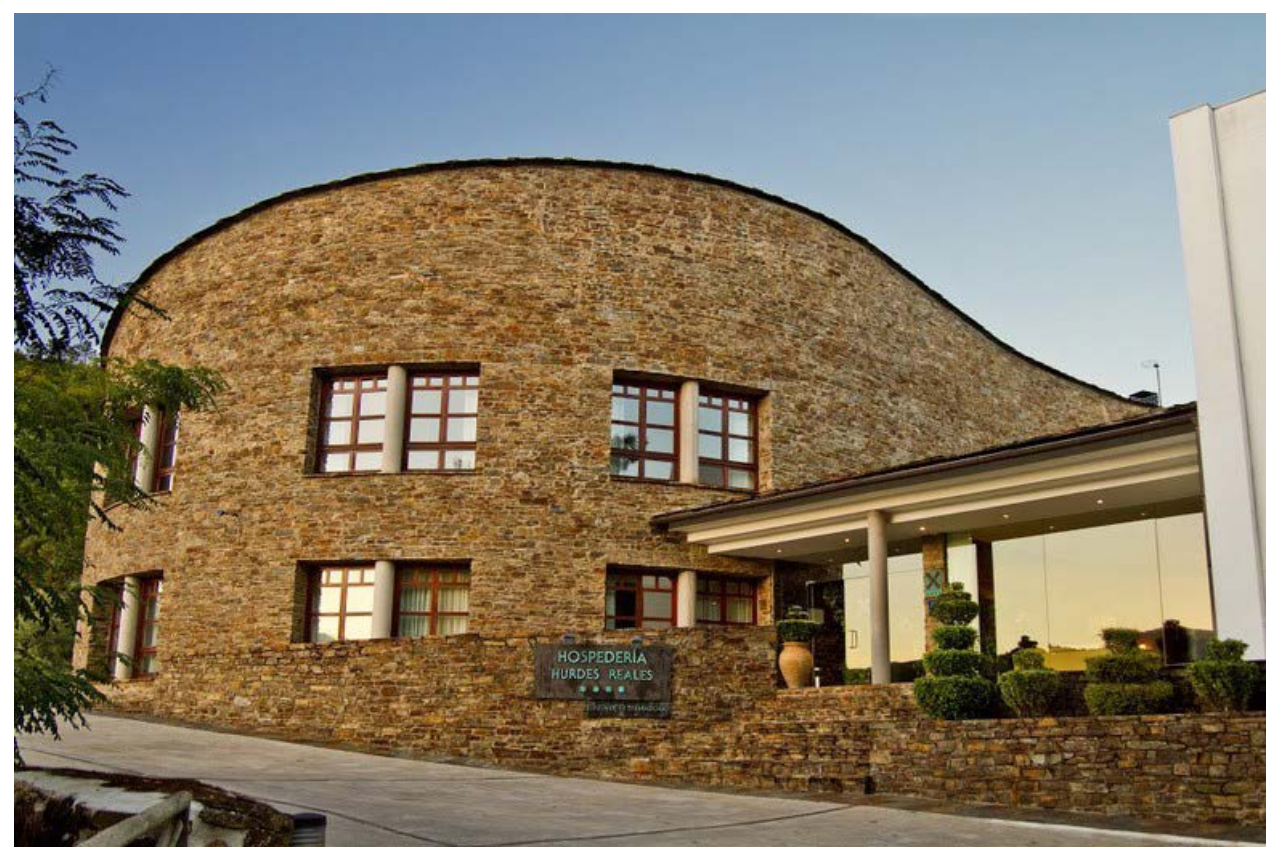

Fuente: https://www.atrapalo.com/hoteles/11830-0_hotel-hospederia-hurdes-reales

El actual hotel, emplazado en el promontorio que acogía la vieja factoría es resultado de la rehabilitación parcial del inmueble y de la construcción de uno nuevo anexo al anterior. El proyecto corrió a cargo de los arquitectos Guillermo Alcón Olivera y Alfonso Bermejo Franco. Los trabajos culminaron en el año 2001, y el establecimiento abrió sus puertas en 2002 .

Las habitaciones se ubican en el núcleo primitivo, que se ha dotado de una planta superior siguiendo la tipología original. El cuerpo de nueva planta alberga los espacios de uso público y de servicios: cafetería, restaurante, salón, lavandería, cocina, etcétera. Una piscina de adultos y otra infantil se recogen dentro del jardín en U que configura la zona destinada a dormitorios. Cuidado césped y abundante arbolado conforman un espacio externo atractivo, lo que se intensifica con espléndidas vistas a los bosques y montes circundantes, que envuelven el hotel y penetran en su vida; sin que lo contrario, sin embargo, ocurra a causa de la espléndida situación elevada del edificio..

En la Hospedería Hurdes Reales es destacable la elección de técnicas y materiales tradicionales de la zona como la mampostería de pizarra para los cerramientos verticales exteriores del cuerpo de uso público, cubierta de teja vieja curva árabe para la zona de habitaciones y de lajas de pizarra en la edificación nueva, carpintería de roble y pino, y suelos de madera, baldosa y pizarra. Sin embargo, el resultado es cualquier cosa menos pintoresco. La zona de habitaciones que se abre al patio se ha pintado de blanco y presenta 
amplios ventanales, lográndose un resultado armónico y depurado, como corresponde a la rehabilitación de un edificio que nunca quiso resultar ostentoso. En cuanto a la fachada principal, de nuevo cuño es llamativo el juego que marca el alabeado de la fachada y su contraste con la marquesina que señala el porche de acceso.

Otra hospedería, la del Jerte, parte de una antigua almazara de principios del siglo XX, cerrada desde finales de la década de los 80 . La historia del edificio se remonta a la primera década de la centuria, cuando se pone en marcha allí una curtidora que funcionó hasta el primer cuarto del siglo XX. En 1933 el empresario Julián Cepeda convierte el único edificio del conjunto que se conservaba en almazara, comprando la maquinaria a la empresa cordobesa de fundición Bernardo Alba Pulido.

El inmueble es sencillo, de mampostería y sillares de granito en los ángulos, planta rectangular, cuatro pisos y cubierta a dos aguas. Como únicos elementos ornamentales sobresalen los balcones enrejados.

En 1992 se convoca un concurso para redactar un proyecto de lo que se denominó mini-parador para el Jerte. El jurado (entre cuyos miembros estaba Sáenz de Oiza) otorgó el premio a la propuesta del equipo integrado por los arquitectos Javier Ruiz y Montaña Luengo, Alfonso Bermejo Franco y Guillermo Alcón Olivera, con un presupuesto de 7.953.400 pesetas (Abujeta, 2015)

La nueva hospedería se inauguró en 1999; pero en 2008 por problemas de gestión cerró. No obstante, dos años después se encargó su ampliación al arquitecto Javier Sánchez Sánchez. Hubo nuevos inconvenientes, y por fin con proyecto de José Timón volvió a abrir sus puertas como hotel de 4 estrellas en 2015 .

Si bien el resultado del proyecto de ampliación es interesante destacando la terrazamirador, se perdió una de las actuaciones más significativas: el jardín japonés que se encarga a los arquitectos ganadores del concurso y que ya en 2007 presentaba un estado de abandono. Asimismo, la maquinaria de la almazara se retiró de su lugar de origen, desvirtuando la propia concepción de conservación patrimonial, y la identidad del conjunto. Esta agresión al patrimonio contrasta con la tendencia a conservar en el sitio los elementos mueles vinculados al edificio. Como ejemplo el Hotel Singular en Puerto Natales (Chile), un hotel de lujo creado sobre el antiguo Frigorífico Bories (1915), declarado monumento histórico en 1996 y donde se ha conservado toda la maquinaria.

Así, en otra de las hospederías extremeñas, la Conventual de Alcántara, inaugurada en 2007 con proyecto de Justo García Rubio, en un antiguo monasterio del siglo XV cuya iglesia fue reconvertida en fábrica mixta de harinas y de luz en 1946, sin embargo, el patrimonio industrial fue cuidadosamente conservado. La Electro-Harinera de Alcántara fue decayendo a finales del siglo XX, y en la década de los 90 se plantea su transformación para uso hotelero. Destaca en esta intervención el mantenimiento de la maquinaria en su lugar original, con un respeto máximo al relato patrimonial, que se complementa con paneles explicativos.

La rehabilitación de cosos taurinos para otros usos es rastreable desde viviendas en Valladolid a hoteles como el Arena Hotel de México o el que nos ocupa el Hotel Plaza de Toros de Almadén es una curiosidad en este conjunto. Construido en 1752 es una de las plazas más antiguas de España dedicada a la actividad taurina. El inmueble, de planta hexagonal, cuyo exterior fue concebido con función residencial. Fue declarada Monu- 
mento Histórico Artístico Nacional en 1979. En estado ruinoso, fue restaurada en 1998 terminándose las obras en 2013. Se transformó en hotel, restaurante y recinto expositivo, conservando su inicial destino taurino el foso.

Por último, mencionar un caso que ha suscitado gran polémica por su impacto ambiental: el complejo hotelero previsto por la empresa Torres y González Díaz en la Playa de los Genoveses en pleno Cabo de Gata, afectando a 26.925 metros cuadrados (Álvarez y Zafra, 2020). Se trata de un entorno protegido, donde se proyecta crear un establecimiento de 30 habitaciones a partir de la recuperación de una explotación agropecuaria de principios del siglo XX, el Cortijo de Las Chiqueras, que existía en la zona antes de su declaración como Parque Natural. El conjunto está constituido por ocho construcciones: nave, corrales, almacenes y viviendas. En su origen, el cortijo estaba dedicado a ganadería, cultivo de cereales y elaboración de esparto.

\section{Figura 8}

\section{CORTIJO DE LAS CHIQUERAS}

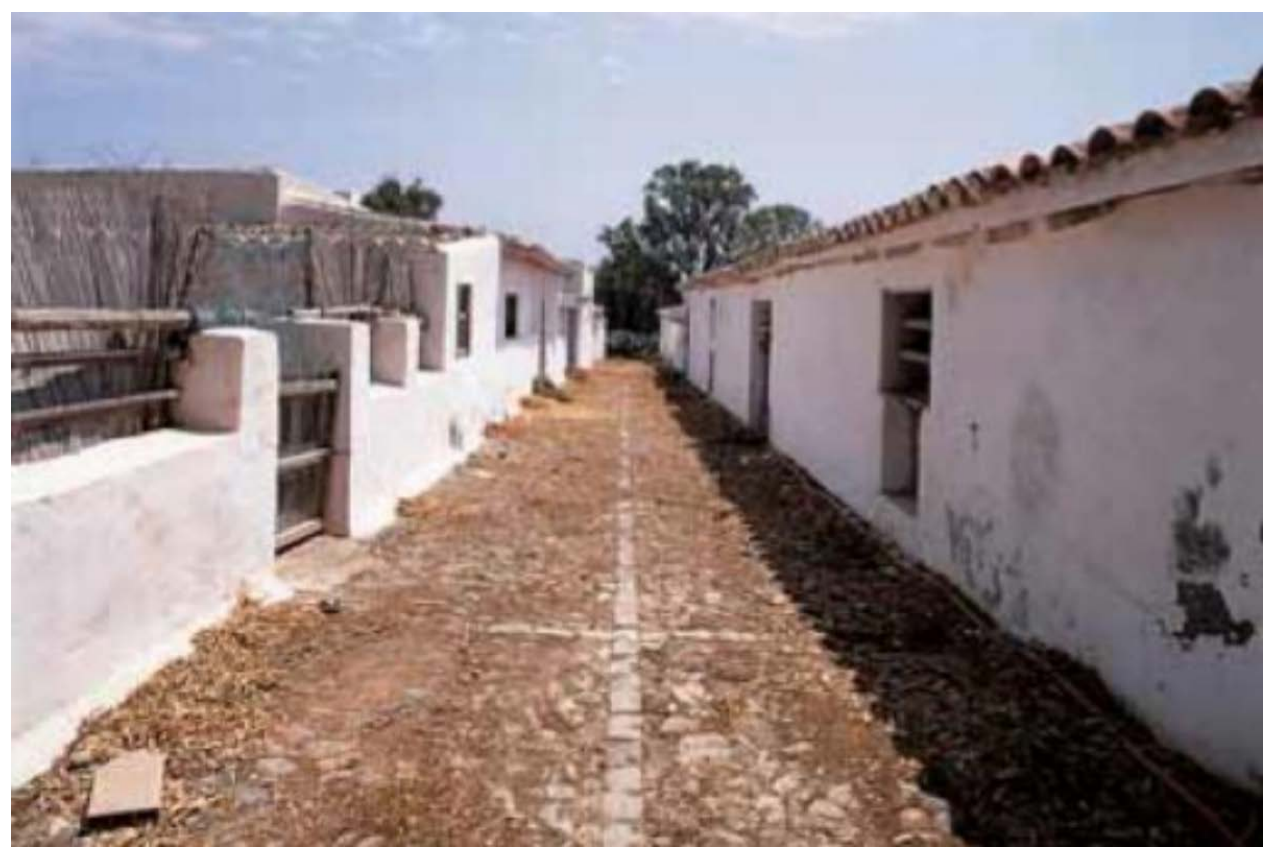

Fuente:https://www.elmundo.es/andalucia/2020/06/28/5ef77bf2fc6c838a618b460c.html

El proyecto prevé utilizar la nave principal (rehabilitada hace años como ecomuseo) para servicios centrales del hotel, la denominada Casa del Pastor pasa a albergar la recepción, y los corrales se convierten en habitaciones. Otras viviendas se transforman también en dormitorios con terraza.

Si bien se dispone de placas solares, y se enfatiza su respecto al entorno, la realidad es que el complejo supondrá un gran impacto para la zona, tanto por el tránsito de vehí- 
culos motorizados como por el efecto llamada que puede suponer para otros cortijos o construcciones de la zona.

Aunque la Junta de Andalucía ha dado el visto bueno al proyecto, son numerosos los colectivos que se oponen, por entender que el desarrollo turístico para el siglo XXI pasa por utilizar los núcleos poblacionales existentes en lugar de crear nuevos en la costa, sobre todo en un área tan sensible como el Cabo de Gata. Recientemente, se ha reabierto la polémica por otro proyecto en la zona, concretamente en El Albardinal.

\section{CONCLUSIONES}

El hotel como atractivo turístico se evidencia en este repaso. El viajero busca conocer lugares; pero lo hace a partir de experimentar sensaciones y emociones que le suscitan su propio alojamiento. Y ello a través de las utopías que el imaginario colectivo vincula al ferrocarril, o la visión romántica del faro.

Destacar los casos en que la exquisitez de la intervención permite la recuperación, junto a los viejos inmuebles, del patrimonio mueble a ellos vinculados; frente a los casos en que la desidia o pura ignorancia hicieron desaparecer o desubicar tan importantes elementos.

Se aprecia así, tras este rápido recorrido por restos industriales en desuso reconvertidos en hoteles que la reutilización de estos viejos contenedores para nuevos usos hoteleros ha servido por una parte para recuperar patrimonio que de otra forma abocaba a la desaparición, mientras por otra se logra una actuación sostenible que evita el despilfarro que supone la nueva construcción, existiendo inmuebles susceptibles de ser transformados.

No obstante, queda de relieve también la paradoja de actuaciones de rehabilitación, como el caso de Cabo de Gata, donde la reutilización puede conllevar un deterioro ambiental, pese a la recuperación patrimonial que en principio supone. Aquí es preciso considerar junto a la mejora visual del conjunto arquitectónico, el umbral de tolerancia y la capacidad de carga del espacio circundante.

En cuanto a tipologías y aspectos formales hay que valorar que, si bien en las últimas décadas sigue siendo tendencia hegemónica en el panorama de la construcción hotelera rural la elección de modelos neopopulares o regionalistas, se evidencian otras líneas de actuación más acordes con postulados modernos y sostenibles. Y cuyos resultados, además de resilientes y medioambientalmente respetuosos, suponen una apuesta por una vanguardia que parece resistírsele al turismo rural, salvo excepciones singulares. Y esto entronca con las ideas del Movimiento Moderno, con la admiración de Le Corbusier por los automóviles o su concepción de la casa como "máquina de habitar"; pues al partir de vestigios industriales se evitan las alusiones historicistas o el socorrido pastiche. Una apuesta, en fin, por un futuro coherente.

Declaración responsable: La autora declara que no existe ningún conflicto de interés relacionado con la publicación de este artículo. 


\section{BIBLIOGRAFÍA Y PÁGINAS WEB}

\subsection{Bibliografía}

ABUJETA, E. (2015): Intervención en el patrimonio arquitectónico extremeño: La red de Hospederías. Tesis doctoral. Universidad de Extremadura.

ADAMS, C. (2004): "La ciudad nueva y la recuperación patrimonial como recursos para el desarrollo local. El caso de Avilés", en Sulcum sevit: Estudios en Homenaje a Eloy Benito Ruano. Oviedo, Universidad de Oviedo, pp. 867-889.

ADAMS, C. (2004): "Visiones del tren. Utopías y realidades", en Rutas culturales y turísticas de Patrimonio Industrial. Gijón, Centro de Iniciativas Culturales y Sociales, pp. 257-264

ADAMS, C. (2017): "Hotel Castillo de Valdés Salas. Una historia de recuperación patrimonial", e-rph. Revista Electrónica de Patrimonio Histórico, n ${ }^{\mathrm{o}}$ 21, pp. 117-136.

ÁLVAREZ, C. y ZAFRA, M. (2020): “Así es el polémico hotel en el parque de Cabo de Gata: corrales convertidos en habitaciones”, Madrid, El País, 9 de julio 2020. Disponible en https://elpais.com/sociedad/2020-07-08/asi-es-el-polemico-hotel-en-elparque-de-cabo-de-gata-corrales-convertidos-en-habitaciones.html

CAMPOS SETIÉN, J.M. DE (2015): Ricardo García Guereta: arquitecto eminente defensor del patrimonio artístico monumental español. Valladolid, Ateneo de Valladolid.

HERNÁNDEZ GUTIÉRREZ, A.S. (1991): Cuando los hoteles eran palacios. Crónica del turismo histórico en Canarias. 1890-1914. Tenerife, Dirección General de Ordenación e Infraestructura turística

MATA PÉREZ, S. (2013): Arquitecturas anheladas, Los palacios obreros de libertarios, católicos y socialistas en España (1860-1930). Tesis Doctoral. Universidad de Valladolid.

RIEGL, A. (1904): El culto moderno a los monumentos, Viena.

SOTELO NAVALPOTRO, J.M. y SOTELO PÉREZ, M (2018).: “Turismo y riesgos naturales en las Rías Baixas gallegas. Estudio de caso", en Cuadernos de Turismo, no42, Murcia.

URRUTIA, Ángel (1997): Arquitectura española. Siglo XX, Madrid, Ediciones Cátedra. VV.AA. (2008).: Extreme hotels. Lisboa, Editorial Estampa.

\subsection{Páginas web}

https://www.fundacionviaverdedelasierra.es/la-via-verde-de-la-sierra-cadiz-sevilla/histo$\mathrm{ria} / 05 / 09 / 2021$

https://www.harpersbazaar.com/es/cultura/viajes-planes/a22639493/hoteles-mas-extranosmundo05/09/2021

https://www.ideal.es/almeria/provincia-almeria/proyectan-tercer-hotel20210325185012-nt.html05/09/2021

http://patrindustrialquitectonico.blogspot.com/2017/07/una-antigua-residencia-ferroviaria. html 05/09/2021 